\title{
METODOLOGIA PARA ANÁLISE DE CONTEÚDO QUALITATIVA INTEGRADA À TÉCNICA DE MAPAS MENTAIS COM O USO DOS SOFTWARES NVIVO E FREEMIND
}

\author{
METODOLOGÍA PARA EL ANÁLISIS CUALITATIVO DE \\ CONTENIDO INTENGRADO CON LA TÉCNICA DE \\ MAPAS MENTALES UTILIZANDO LOS SOFTWARES \\ NVIVO Y FREEMIND
}

José Leonardo Oliveira Lima*

Miriam Paula Manini**

\begin{abstract}
RESUMO:
Introdução: Em uma pesquisa, não basta escolher os instrumentos, recursos e procedimentos. É importante compreender o método, para além da técnica, e a sua relação com a filosofia, epistemologia e metodologia.

Objetivo: Apresentar reflexões teóricas e metodológicas sobre a Pesquisa Qualitativa na Ciência da Informação e sobre o processo de Análise de Conteúdo Qualitativa (ACQ) no campo de Estudos de Usuários e demonstrar um percurso empreendido de $A C Q$ integrado à técnica dos Mapas Mentais para o desenvolvimento de categorias e indicadores, com a utilização de softwares de apoio à Análise de Dados Qualitativa (QDAS) e de desenho de Mapas Mentais.

Metodologia: A pesquisa foi descritiva, metodológica, bibliográfica e de campo, tendo como instrumento as entrevistas abertas, que foram processadas utilizando a ACQ e a técnica dos Mapas Metais, com o apoio do QDAS Nvivo e do Software FreeMind de desenho de mapas mentais.

Resultados: Demonstra-se aspectos da teoria da pesquisa qualitativa e da ACQ e um percurso metodológico de ACQ usando as técnicas e softwares mencionados, de forma integrada.

*Doutor em Ciência da Informação pela Universidade de Brasília (UnB), Professor na Universidade Estadual de Goiás (UEG), Sistemas de Informação. E-mail: jjleo@ueg.br

**Doutora, Docente na Universidade de Brasília (UnB) - Faculdade de Ciência da Informação $(\mathrm{FCl}$ ) - Programa de Pós-Graduação em Ciência da Informação. E-mail mpmanini@uol.com.br
\end{abstract}


Conclusões: Nas pesquisas qualitativas, o referencial teórico sugere a necessidade de mais diálogo da Ciência da Informação com outras disciplinas. O processo de ACQ, com o uso do QDAS, explicitou um percurso viável que pode servir de referência para outras investigações. Evidenciou-se a contribuição da técnica e do software de desenhos de Mapas Mentais, no desenvolvimento das categorias e indicadores da $A C Q$.

Palavras-chave: Métodos de pesquisa. Análise de conteúdo. Análise qualitativa. Estudos de usuários. Programas de computador.

\section{INTRODUÇÃO}

Um processo de pesquisa que trabalha com abordagens qualitativas apresenta uma riqueza que vai além da definição da metodologia a priori conforme inicialmente previsto em um projeto ou plano de pesquisa - e sua execução.

Em uma pesquisa, não basta escolher os instrumentos, recursos e procedimentos relacionados com o processo da investigação. É importante compreender o método, para além da técnica, a sua relação com a filosofia, epistemologia e metodologia, compreendendo as teorias de base, fazendo a aplicação e, mesmo, resignificando o método (ou os métodos) conforme as especificidades do objeto da pesquisa.

$\mathrm{Na}$ literatura científica, vê-se muitas discussões a respeito da pesquisa qualitativa com o uso de softwares para apoiar o processo, mas pouca apresentação que detalha os processos metodológicos e técnicas usadas, integradas às tecnologias com o devido embasamento teórico (KAEFER; ROPER; SINHA, 2015).

No presente artigo, além das reflexões teóricas e metodológicas relacionadas com as pesquisas qualitativas e a análise de conteúdo na Ciência da Informação $(\mathrm{Cl})$ e a consequente correlação com um processo prático de investigação, propõe-se, também como contribuição: i) apresentar alguns aspectos orientadores para a escolha de um Software de Análise Qualitativa de Dados (QDAS); ii) a utilização dos mapas mentais como técnica de apoio para se chegar às categorias e Indicadores de Análise de Conteúdo; iii) demonstrar 
um percurso de Análise de Conteúdo Qualitativa com uso do QDAS Nvivo do Software FreeMind de desenho de Mapas Mentais.

O objeto da pesquisa está relacionado com o campo de "Estudos de Usuários" da Ciência da Informação ( $\mathrm{Cl}$ ), envolvendo o levantamento das necessidades de informação de docentes (usuário da informação) em processo de avaliação na Educação a Distância, cujo breve contexto apresentamos na sequência para compreensão do ambiente em que ocorreu o processo de Análise de Conteúdo Qualitativa.

Na Educação a Distância "em linha" - que é favorecida pelos recursos e possibilidades das Tecnologias da Informação e Comunicação -, os Ambientes Virtuais de Aprendizagem possibilitam a interação entre estudantes e professores, promovendo a colaboração e discussão de ideias, disponibilização de atividades e materiais de estudo (textos, fotografias, vídeos, animações etc.), avaliações, construção colaborativa por meio de fóruns e listas virtuais de discussão, bate-papo, áudio e videoconferência etc. (MOORE; KEARSLEY, 2007).

Contudo, a avaliação de estudantes que utilizam os Ambientes Virtuais de Aprendizagem (AVA) e dos processos de interação a distância se tornam cada vez mais desafiadores para o professor.

Muitos dos AVAs já apresentam alguns recursos de avaliação, porém com relatórios e informações muito detalhadas sobre cada aluno, acesso a cada recurso do sistema, logs ${ }^{*}$ de uso do ambiente etc. Tais informações são pouco (ou quase nunca) usadas, pois são muito complexas para um professor fazer análise pormenorizada e obter elementos que o auxiliem na avaliação, conforme também constatou Silva (2011), sem contar que muitos desses recursos foram propostos por profissionais de TI sem a devida percepção das necessidades do usuário da informação: o docente.

Faltam informações sintéticas e significativas (inclusive com gráficos e ${ }^{*}$ Logs - Arquivo de registro automático de todas as operações realizadas por um usuário em
um sistema ou ambiente.

Inf. Inf., Londrina, v. 21, n. 3, p. 63 - 100, set./dez., 2016. 
elementos visuais) que tenham sido desenvolvidas a partir das necessidades do docente e do processo ensino-aprendizagem, que auxiliem o professor a detectar não conformidades, e poder avaliar, de forma mais justa e consistente, a participação e o desenvolvimento do conhecimento do aluno em um curso por intermédio de um Ambiente Virtual de Aprendizagem (AVA).

Face ao que sucintamente expusemos, teve-se, então, como problema de pesquisa: quais são as necessidades de informação dos docentes na avaliação de estudantes de graduação a distância, mediada por Ambientes Virtuais de Aprendizagem?

Para responder a este problema, optou-se por um processo que envolveu uma pesquisa com abordagem qualitativa de estudo de usuários da informação, utilizando o processo de Análise de Conteúdo, com o uso integrado dos softwares já mencionados.

\section{ELEMENTOS TEÓRICOS E METODOLÓGICOS PARA O PROCESSO DE PESQUISA QUALITATIVA EM CI}

A Ciência da Informação, ainda como uma ciência nova, está em fase de sedimentação dos aspectos filosóficos, epistemológicos e metodológicos, como apresentam Bates (1999), Hjørland (2005), Capurro e Hjørland (2007) e Cibangu (2013), dentre diversos outros autores.

Já se tornou lugar comum a referência de que a Ciência da Informação, pela natureza da sua gênese de surgimento, é interdisciplinar. Autores como Saracevic (1995, 1996), Bates (1999), Le Coadic (2004), entre outros, explicitam e fundamentam muito bem a questão da interdisciplinaridade.

Hjørland (2005) - no capítulo de abertura do número especial sobre a Ciência da Informação e a Filosofia da Ciência publicado no Journal of Documentation - enfatiza a importância das reflexões da filosofia e da epistemologia para a Ciência da Informação e o quanto referidos estudos ainda são incipientes na Ciência da Informação, carecendo de uma compreensão mais aprofundada dos referidos aspectos para sedimentar a Ciência da Informação como uma ciência calcada em princípios teoricamente sólidos e 
melhor fundamentados. Passados oito anos da publicação do número especial do Journal of Documentation, Cibangu (2013) coloca as mesmas questões, demonstrando que pouca coisa mudou.

Paradoxalmente, no que se refere à filosofia, metodologia e epistemologia, a Ciência da Informação ainda tem um diálogo muito pequeno com as Ciências Sociais e Sociais Aplicadas, que poderiam oferecer grandes contribuições, principalmente nas pesquisas de caráter qualitativo, pensamento esse que é corroborado por Fidel (2008) e Cibangu (2013). Apesar de, em outras áreas como Educação, Psicologia, Sociologia, Antropologia etc., a pesquisa com abordagens qualitativas ser muito utilizada, com muitos trabalhos desenvolvidos e um consistente referencial teórico, na $\mathrm{Cl}$ a utilização de abordagens qualitativas ainda é limitada, como problematizam Fidel (2008) e Cibangu (2013).

$\mathrm{Na}$ filosofia e epistemologia, existe, ainda de forma calorosa, o embate teórico entre:

- As concepções de caráter positivista ou pós-positivista - que dão mais ênfase às abordagens quantitativas, ao método cartesiano, nos processos de indução e dedução e da lógica hipotético-dedutiva (que atendem as necessidades das ciências da natureza), entre outras;

- As concepções de caráter mais holístico, relacionadas ao denominado paradigma pós-moderno, que têm como pressupostos teóricos o interpretivismo, a hermenêutica, o construtivismo etc., dão ênfase às abordagens qualitativas e métodos como o da Análise de Conteúdo, da teoria fundamentada (grounded theory), da etnografia, entre outras, mais relacionadas com as Ciências Sociais.

Lincoln e Guba (2006) falam da mudança no pensamento científico. Se antes os paradigmas denominados pós-modernos (teoria crítica, interpretivismo e construtivismo) disputavam "legitimidade intelectual com os paradigmas positivistas e pós-positivistas geralmente aceitos e com legitimidade intelectual entre si” (LINCOLN; GUBA, 2006, p. 169), a realidade atual já demonstra a 
legitimidade dos paradigmas pós-modernos, que, segundo os autores, estão bem aceitos e se igualam aos paradigmas convencionais. Os limites entre os paradigmas estão se modificando e o conceito é equivalente ao "obscurecimento dos gêneros" (GETZ apud LINCOLN; GUBA, 2006, p. 172), que remete aos consensos da comunidade científica "no que diz respeito ao que é real, ao que é útil e ao que tem sentido" (HERON; REASON, 1997 apud LINCOLN; GUBA, 2006, p. 172).

A teoria tem o papel de problematizadora e orientadora para muitos aspectos que, na prática, estão acontecendo, às vezes, sem a devida fundamentação, problematização ou reflexão. Compete às epistemologias gerais e às epistemologias específicas (no caso, aqui, da $\mathrm{Cl}$ ) buscarem a densidade e a fundamentação filosófica e epistemológica que possam nortear futuros estudos e pesquisas.

Contudo, a falta do entendimento e amplitude teórica do que ocorre na prática não pode ser justificativa para a inércia, do mesmo jeito que, se as pesquisas na $\mathrm{Cl}$ focarem somente na prática, sem busca do aprimoramento dos fundamentos teóricos (ou pelo menos do conhecimento das lacunas que ainda existem e que precisam ser preenchidas e que podem dialogar com os achados das demais disciplinas), incorre-se no risco de cair em outras formas de conhecimento de senso comum e pouco fundamentados, que também não contribuem para a revisão da ciência à luz dos desafios contemporâneos. Como observa Demo (1995, p. 85): "Não vale a crítica radical sem prática, porque se destrói a si mesma: não muda nada e, por cima, confere ares de democracia ao sistema criticado, pois sustenta o crítico. Nem vale a prática sem teoria, porque será ignorante".

A pesquisa qualitativa envolve um processo dialógico entre o que originalmente foi pensado e a riqueza da dinâmica e do confronto com a realidade complexa que vai sendo descortinada ao longo da investigação. Dessa relação surgem elementos que reorientam e redefinem o processo de pesquisa, trazendo a importância do diálogo com a realidade, o aprimoramento e sistematização do pensamento e dos construtos teóricos, que ocorrem com a clarificação e aproximação do pesquisador com o objeto de estudo e o 
amadurecimento decorrente do processo. Por isso Rubim e Rubim (1995 apud FLICK, 2009a, p. 107) sugerem a importância de se ter um "desenho flexível, iterativo e contínuo".

Flick (2009b) - referenciando Glasser e Strauss (1967); Strauss e Corbin (1990); Strauss (1989), dentre outros autores - apresenta que as pesquisas tradicionais de orientação positivista seguem um enfoque linear, partindo da construção de um modelo proposto por um desenho de pesquisa, sendo que o ponto de partida é o conhecimento teórico extraído da literatura ou das descobertas teóricas até então existentes; propõe hipóteses que são decompostas em variáveis, operacionalizas e testadas empiricamente.

$\mathrm{Na}$ abordagem de caráter qualitativo, a perspectiva amplia-se, pois busca incluir o contexto em que a pesquisa se insere, quebrando a linearidade, desenvolvendo-se em um processo circular que repensa e redefine o processo e suas etapas, em diversos instantes, com uma interdependência mútua das etapas isoladas do processo de pesquisa conforme as necessidades do objeto de pesquisa (FLICK, 2009b).

As teorias, no processo de pesquisa que envolve abordagens qualitativas, são compreendidas como versões do mundo, perspectivas a partir das quais o mundo é percebido, sem um julgamento de certo ou errado, mas preliminares e relativas, conduzindo a um aprimoramento do referencial teórico e do processo de pesquisa empírica em relação ao objeto que é pesquisado, como apresenta Flick (2009b, p. 98).

Nas pesquisas com abordagens qualitativas, o problema de pesquisa, os objetivos gerais e objetivos específicos (ou as questões da pesquisa) são elementos norteadores, para que o pesquisador não se perca no processo. Contudo, as questões da pesquisa podem ser revistas, aprimoradas e ampliadas, desde que se mantenha o foco, a delimitação do assunto e a perspectiva de análise; as etapas podem ser redefinidas conforme o desenvolvimento e amadurecimento provocado pela pesquisa. Demo (1995) pondera que, apesar da amplitude de possibilidades no desenvolvimento do percurso, há que se ter cuidado com o excesso de relativismo em pesquisas sociais de caráter qualitativo, em que tudo é possível e nada é controlado ou 
sistematizado, o que pode escamotear falta de rigor e de consistência teórica.

Quando trazemos a discussão do processo de pesquisa para a $\mathrm{Cl}$, Cibangu (2013), citando a pesquisa de Fidel (2008), pondera sobre a pouca explicitação da abordagem de caráter qualitativo, sendo que, nas pesquisas em que são usadas, muitas vezes nem são identificadas como tal. Um cuidado importante de ser observado, para o qual Gibbs (2009) alerta, é sobre a importância de se explicitar, de forma mais evidente, a natureza do caráter qualitativo da pesquisa, tanto nos níveis teóricos, metodológicos e práticos de pesquisa, como na interpretação de resultados.

$\mathrm{Na}$ sequência, apresentamos, de forma mais detalhada, alguns pressupostos teóricos da Análise de Conteúdo, os softwares de apoio a Análise Qualitativa de Dados e a Técnica e softwares de apoio à construção de mapas mentais, para posteriormente fazer a junção de tudo por intermédio do desenho metodológico da pesquisa e, finalmente, apresentar o embate da prática de um percurso de pesquisa com os fundamentos teóricos, métodos, técnicas e recursos escolhidos.

\subsection{A Análise de Conteúdo}

A Análise de Conteúdo (AC) segue os pressupostos da hermenêutica. $O$ termo hermenêutica partindo do seu uso e contexto histórico remoto significa a "arte de interpretar os textos sagrados ou misteriosos". Na contemporaneidade é usado para determinar uma corrente filosófica. Na ciência, caracteriza-se também como uma metodologia que utiliza dos aspectos simbólicos e polissêmicos por trás do discurso que é possível desvendar. Na Análise de Conteúdo, a atitude interpretativa da concepção inicial do termo continua, mas suportada por processos técnicos de validação (BARDIN, 2011, p. 20). Referida autora coloca que a Análise de Conteúdo não é uma técnica, mas um conjunto de técnicas de análise de comunicações.

Henry e Mocovici (apud BARDIN, 2011, p. 38), ainda nos primórdios da $A C$, afirmaram que "tudo o que é dito ou escrito é suscetível de ser submetido a uma Análise de Conteúdo". Bardin, ampliando essa posição, contra-argumenta que, com os estudos da comunicação não linguística (semiótica ou semiologia), 
tudo o que é comunicação (e mesmo significação) parece ser suscetível de análise. Assim, devido à amplitude de possibilidades da referida afirmação, Bardin propõe dois critérios para definir o que pode ser objeto de estudo da Análise de Conteúdo: a) a quantidade de pessoas envolvidas na comunicação - monólogo, duas pessoas (dual), um grupo restrito ou comunicação de massa; b) a natureza do código e do suporte - linguístico (escrito ou oral), icônico (sinais, imagens, fotografias etc.), outros códigos semióticos (o que não é linguístico, mas portador de significações como gestos, objetos diversos, código olfativo etc.).

A Análise de Conteúdo, segundo Bardin (2011, p. 50), "visa o (sic) conhecimento de variáveis de ordem psicológica, sociológica, histórica etc., por meio de um mecanismo de dedução com base em indicadores reconstruídos a partir de uma amostra de mensagens particulares". A intenção é a inferência de conhecimentos, recorrendo aos indicadores, podendo esses ser quantitativos ou não. Para a autora,

[...] se a descrição (enumeração das características do texto, resumida após tratamento) é a primeira etapa necessária e se a interpretação (a significação concedida a estas características) é a última fase, a inferência é o procedimento intermediário, que vem permitir a passagem, explícita e controlada, de uma à outra (BARDIN, 2011, p. 45).

A Análise de Conteúdo pode ser uma análise tanto dos "significados" quanto dos "significantes", como, por exemplo e respectivamente, são a "análise temática" e "análise de procedimentos".

A Análise de Conteúdo clássica (temática, com quadro categorial, privilegiando a repetição de frequência dos temas) acaba por percorrer ao nível manifesto as entrevistas, ficando, às vezes, excluída parcela "das significações produzidas pelas pessoas, deixando escapar o latente, o original, o estrutural, 0 contextual" (BARDIN, 2011, p. 95).

No caso, por exemplo, de entrevistas, tão importante quanto a análise temática, com a justaposição de elementos comuns explicitados (ou não explicitados - o silêncio e as omissões também são elementos importantes na 
AC) dos diversos participantes ou objetos pesquisados, é a leitura vertical da fala dos entrevistados, que Bardin (2011, p. 94-97) intitula de "análise da enunciação". Segundo a autora, ao realizar o estudo processual, envolvendo cada fala, pode-se perceber os silêncios e omissões, o contraditório, as emoções, a afloração do inconsciente etc.

Uma corrente que tem se fortalecido muito nas últimas décadas é denominada Análise de Conteúdo Qualitativa (Qualitative Content Analysis), que, de uma certa forma, faz uso do método misto de pesquisa, uma vez que se vale do processo qualitativo na essência, mas também utiliza dos elementos quantitativos que possam aprimorar e contribuir para os processos de análise e inferência dos dados (MAYRING, 2014). Como já colocado anteriormente, as pesquisas podem ser complementares entre si, sendo que o processo de caráter mais qualitativo pode se apoiar nos elementos quantitativos e viceversa.

No processo de Análise de Conteúdo, seja seguindo uma abordagem quantitativa ou qualitativa, conforme proposto por Bardin (2011), são realizadas as seguintes etapas:

\subsubsection{A pré-análise}

É nessa etapa que se faz a leitura flutuante e começam a surgir as primeiras hipóteses do processo de análise de conteúdo, que podem facilitar a descoberta de caminhos que ajudam no processo de investigação do conteúdo.

As hipóteses não são obrigatórias - principalmente nos casos que privilegiam os procedimentos exploratórios na Análise de Conteúdo, como preconiza Moscovi (apud BARDIN, 2011, p. 129). As hipóteses, mesmo não explicitadas formalmente, podem surgir no processo de pesquisa como suposições, ou ficam implícitas em função do problema de pesquisa, objetivos e/ou questões da pesquisa, que nortearão a escolha dos índices, indicadores e categorias.

O índice pode ser a menção explícita de um tema numa mensagem. Caso parta do princípio de que este tema possui tanto mais importância para o locutor quanto mais frequentemente é repetido (caso da análise sistemática 
quantitativa), o indicador correspondente será a frequência [...] escolhidos os índices, procede-se a (sic) criação de indicadores precisos e seguros (BARDIN, 2011, p. 130).

No caso dos índices qualitativos, esses podem ser o conteúdo das falas concordantes entre os entrevistados, os silêncios (aquilo que não é abordado) etc., que serão identificados por indicadores.

Desde a fase da pré-análise já se inicia a visualização, o destaque e os "recortes" de textos (os índices) nas unidades mais básicas de categorização, que são os indicadores.

Também é na pré-análise que são escolhidos os procedimentos de categorização, que serão detalhados em seção mais a diante.

\subsubsection{A codificação}

Antes de iniciar a codificação, procede-se à escolha da unidade de registro e da unidade de contexto.

A unidade de registro "é a unidade de significação codificada e corresponde ao segmento considerado unidade base" (BARDIN, 2011, p. 134). Pode ser a palavra, o tema, a frase, a depender da especificidade do objeto de pesquisa e das necessidades do pesquisador.

A unidade de contexto é está relacionada com a unidade de significação, ou seja a perspectiva (ou as perspectivas) pela(s) qual(is) vai se analisar a unidade de registro. Esse é um elemento importante, principalmente quando a análise de conteúdo envolver grande quantidade de dados e o processo de codificação precisa ser realizado por diversas pessoas, como Bardin adverte, para que todos os codificadores sigam o mesmo contexto, escopo e abrangência de compreensão da unidade de registro.

Também é nesse momento que se pode determinar as regras de enumeração, envolvendo a relação entre as unidades de registro, que podem ser: contagem, intensidade, presença (ou ausência) de conteúdos no material analisado, frequência com que ocorre, entre outras. Esse aspecto tem um caráter mais quantitativo, mas são elementos que podem auxiliar nos processos de inferência na Análise de Conteúdo Qualitativa. 
É na codificação que serão utilizados os indicadores pensados na fase de pré-análise, observando os quesitos de exaustividade, onde se recomenda que toda unidade de registro deve ser analisada e devidamente classificada.

Quando se faz o uso de softwares de apoio à Análise de Dados Qualitativa, a codificação é a ação de atribuição de índices (conteúdos) conforme a unidade de registro escolhida - aos indicadores. Os indicadores, dependendo do software, podem ter nomes variados: código, Nó etc.

\subsubsection{A categorização}

Com os dados codificados, procede-se à categorização (usando procedimentos taxonômicos), que, diga-se de passagem, não é obrigatória, apesar da confusão de se achar que a Análise de Conteúdo é sinônimo de categorização. Esse é um equívoco comum, conforme observam Dellagnelo e Silva (2005).

Categorizar é organizar um conjunto de "coisas" em categorias, subcategorias e assim sucessivamente, observando, a partir de um determinado critério, o que cada coisa tem em comum.

Os procedimentos de categorização podem ser: a) fechados, quando a escolha das categorias de análise acontecem a priori, a partir de um quadro operacional fixo, que foi montado utilizando como referencial outros estudos, outras pesquisas, taxonomias de estudos equivalentes já utilizados etc.; b) procedimentos de exploração, que permitem encontrar ligações entre as diversas variáveis, podendo as categorias serem montadas com base na pesquisa realizada; c) híbridos (DELLAGNELO; SILVA, 2005), podendo utilizarse um quadro de referência a priori e deixar esse ser aprimorado, definido e redefinido durante os procedimentos de exploração.

Nos procedimentos fechados, o processo de categorização é considerado dedutivo, pois parte de uma premissa existente (categorias préexistentes) que vai se aplicar à nova análise, muito utilizado em processos de pesquisa quantitativa. Nos procedimentos de exploração o processo geralmente é indutivo, partindo das categorias que vão surgindo e sendo reorganizados durante a análise de conteúdo (MAYRING, 2014). 
Dellagnelo e Silva (2005, p. 112) apresentam que:

[...] de acordo com Bardin, os critérios de categorização podem ser: - semânticos (categorias temáticas: por exemplo, os elementos que refletem ansiedade serão agrupados em uma categoria ansiedade; os elementos que refletem valores individualistas serão agrupados em uma categoria individualismo); - sintéticos (verbos, adjetivos, advérbios, etc.); léxico (ordenamento interno das orações); - expressivos (por exemplo, categorias que classificam os problemas de linguagem).

"A categorização tem como primeiro objetivo [...] fornecer, por condensação, uma representação dos dados brutos. Na análise quantitativa, as inferências finais são, no entanto, efetuadas a partir do material reconstruído" (BARDIN, 2011, p. 149). Na análise qualitativa, as categorias também conduzem ao processo de inferência, de condensação, de resumo e de síntese dos assuntos frutos da análise de conteúdo.

\subsubsection{A inferência/interpretação}

Com os dados organizados, procede-se à análise, à inferência, à redução dos dados (quando da utilização de elementos quantitativos) e à interpretação dos elementos qualitativos contidos nos índices, fazendo o diálogo com os referenciais teóricos do pesquisador, sendo importante também colocar a percepção e intuição a serviço da análise para se chegar à síntese.

A interpretação é o momento em que o pesquisador se debruça sobre os dados, fazendo-os expressar (ou não) os elementos necessários para a elucidação de seu objeto de estudo e de suas hipóteses.

Essa etapa exige criatividade, retorno aos dados múltiplas vezes e análise das suposições inicialmente propostas para testar a validade ou não.

É aqui que alcançamos efetivamente os objetivos propostos pela Análise de Conteúdo. Apesar de ser uma etapa, evidentemente, crucial da análise, nesse momento o método já não nos é de grande utilidade senão naquilo para o que ele já pôde colaborar, se as fases anteriores foram bem realizadas (DELLAGNELO; SILVA, 2005, p. 113). 
É nesse momento que se coloca em prática as técnicas de Análise de Conteúdo, que podem ser: temática, de enunciação (as quais já abordamos), de avaliação e de expressão, entre outras sugeridas por Bardin (2011).

Convém ressaltar que as etapas da Análise de Conteúdo, como mostram Bardin (2011) e Krippendorff (2013), não são necessariamente sequenciais, podendo, no momento da categorização, retornar à codificação, a algum elemento de pré-análise etc. Contudo, é importante observar que, se for efetuada alguma mudança nos indicadores, categorias etc., recomenda-se que todo o material seja revisto, observando o critério da exaustividade, para não correr o risco de se ter dados codificados inadequadamente em virtude de critérios diferentes utilizados em uma mesma pesquisa em momentos diversos. Daí a importância da etapa da pré-análise.

\subsection{Os Softwares de Análise Qualitativa de Dados}

Com o advento das Tecnologias da Informação e Comunicação (TIC), a forma de se fazer pesquisa mudou consideravelmente. Os recursos computacionais disponíveis atualmente para Análise Qualitativa de Dados são uma realidade que se juntam às diversas práticas de pesquisa qualitativa.

Análise Qualitativa de Dados não está condicionada ao uso de softwares. É possível fazer as análises manualmente, recortando papeletas impressas e justapondo ideias correlatas como era, por exemplo, o processo manual nos primórdios da Análise de Conteúdo [vide Bardin (2011)] ou mesmo usando, por exemplo, o copiar e colar dos Editores de Texto e suas ferramentas de busca de palavras.

Os softwares de propósito geral, como Editores de Texto, Planilhas Eletrônicas e Banco de Dados, podem ser usados no processo a Análise de Dados Qualitativa. É possível, com esses recursos, contar frequência, fazer buscas e analisar os dados ali dispostos. Como exemplo há as pesquisas de Nideröst; Meyer, Gru e Franz (apud GIBBS; FRIESE; MANGABEIRA, 2002), que utilizaram, respectivamente: o Editor de Texto Word para o processamento de pesquisa qualitativa; o Gerenciador de Banco de Dados Access para análise de Respostas Abertas em Questionários e Entrevistas. Contudo, como referidos 
softwares não foram construídos com a finalidade de desenvolver a análise qualitativa de dados, vão exigir do usuário mais conhecimentos técnicos, capacidade de adaptação e criatividade para superar as limitações dos softwares.

Fazer a análise de dezenas, centenas ou milhares de unidades de materiais de pesquisa de, por exemplo, entrevistas exploratórias abertas, questões abertas de questionários, textos de jornais, revistas, blogs e sítios da internet, entre outros, é um processo muito dispendioso e complexo, para não dizer impossível de ser feito, em alguns casos, com a devida qualidade sem que isso não consuma um tempo muito maior do que geralmente o pesquisador e/ou equipe dispõem. Imagine então estratificar dados para análise, fazer correlações, remontar os dados em diversos rearranjos para tentar extrair a informação necessária utilizando diferentes fontes de informação em conjunto: texto, áudio, vídeo, imagens, fotos etc.?!

É nesse ponto que entra a Análise de Dados Qualitativos Apoiados por Computador (Computer Assisted Qualitative Data AnalysiS - CAQDAS), que é considerada, inclusive, um campo eclético de pesquisa que atua no contexto da metodologia da pesquisa qualitativa e das técnicas de análise em geral, com diferentes tradições filosóficas, teóricas e metodológicas. Os pacotes de CAQDAS funcionam como um sistema integrado que permite planejar e gerenciar seu projeto de pesquisa qualitativa em diferentes aspectos (LEWINS; SILVER, 2014).

Os pacotes de CAQDAS modernos, também conhecidos como Softwares de Análise Qualitativa de Dados (Qualitative Data Analysis Software - QDAS), favorecem: a gestão integrada dos inúmeros materiais, fontes e recursos de pesquisa; a codificação de indicadores (indexação); a categorização; e a utilização de recursos variados em uma mesma análise: textos, áudios, imagens e vídeos de materiais em diversos formatos (editor de texto, PDF, RTF, GIF, JPEG). Propiciam a busca, a recuperação e estratificação necessárias para as diversas etapas do processo de análise qualitativa. Contribuem nos processos cognitivos humanos de análise e a redução dos dados (síntese), facilitando a busca e a recuperação de informações com a 
utilização de operadores booleanos (e, ou, não), matrizes dinâmicas de dados, permitindo uma multiplicidade de combinações das informações e rearranjos. Geram tabelas, gráficos de frequências, nuvens de palavras, indexação de diversos itens etc. Possuem editores de texto integrados que permitem anotações de observações, memorandos que podem ser usados para insights, observações, comentários pessoais ao longo do processo de análise. Alguns até se propõem a auxiliar em processos de codificação automática, usando inclusive alguns recursos computacionais de inteligência artificial, apesar desses recursos ainda serem uma promessa e limitados.

Outra vantagem de referidos softwares é que eles concentram todos os recursos necessários para uma análise, sendo que o pesquisador e a equipe, ao abrirem um projeto (muitos dos QDAS permitem vários usuários interligados em rede), terão disponíveis todas as fontes de informação necessárias para o processo (por exemplo, entrevistas, imagens, gráficos, textos etc). Também tem a possibilidade de fazer links com referências a conteúdos externos que são facilmente acessados pelos Softwares (LEWINS; SILVER, 2015).

O principal requisito para uma análise qualitativa adequada é um eficiente, consistente e sistemático gerenciamento de dados, para busca e recuperação da informação (GIBBS; FRIESE; MANGABEIRA, 2002).

Os softwares são instrumentos de apoio ao processo de análise, porém não fazem a análise pelo(s) pesquisador (es). Essa é uma tarefa meramente intelectual, abstrata e complexa que nenhum QDAS, pelo menos até o momento, é capaz de realizar. Contudo, isso ainda é uma expectativa de muitos dos que se iniciam no processo de análise qualitativa com o apoio de softwares. Como pondera Wolcott, os aspectos conceituais da análise que incluem, por exemplo, ler um texto, interpretar, criar esquemas de codificação e identificar pesquisas e relatórios pertinentes necessitam da atividade intelectual humana e não podem ser feitos por máquinas (WOLCOTT apud GIBBS; FRIESE; MANGABEIRA, 2002).

Um aspecto digno de nota é que o software não é o método ou a metodologia. Essa é outra confusão muito comum. Apesar de alguns softwares terem sido concebidos pensando em um pressuposto teórico ou em uma 
abordagem metodológica (por exemplo, a hermenêutica é a concepção por trás do desenvolvimento do Atlas.ti), é importante que o pesquisador tenha clareza dos pressupostos teóricos e metodológicos de sua pesquisa e como esses podem (e se podem) ser executados no software de escolha. Geralmente, a maioria dos softwares são ferramentas genéricas, que possibilitam diversas abordagens metodológicas; porém, alguns podem ter algumas limitações. Cabe ao pesquisador problematizar, previamente, sobre os aspectos da base teórica, epistemológica e metodológica da sua pesquisa para se certificar que o software que pretende usar consegue dar suporte às especificidades.

Outra questão comum e para a qual não existe resposta pronta: qual o melhor software para análise qualitativa de dados? Faz-se necessário considerar o que será objeto da análise, os pressupostos que nortearão o processo - como mencionados anteriormente -, quais recursos básicos serão necessários (texto, imagens, áudio, vídeo etc.), como será feita a organização dos dados no software etc. Com essas informações se deve, então, fazer o levantamento dos softwares existentes, quais suas possibilidades e limitações, como é feito o processo de codificação da informação, como é feito o processamento da informação, quais as facilidades na busca e recuperação da informação no processo de análise, entre outras coisas.

Não existe software perfeito ou que possa ser o melhor em tudo, porém existe aquele que melhor atende a um conjunto de necessidades. Por outro lado, não é por que um software tem inúmeras funcionalidades, as quais talvez o usuário nunca irá utilizar, que deverá ser o escolhido. Deve-se olhar para o que se pretende fazer, com uma perspectiva de longo prazo - afinal, é um investimento, para que o software escolhido melhor atendas suas necessidades presentes e futuras e o investimento seja adequado para o que se propõe (LEWINS; SILVER, 2015).

Como exemplos de Softwares de Análise Qualitativa de Dados, citamos os Atlas.ti, NUD*IST, Nvivo, MAXQDA, QDAMiner e QDAMiner 4 lite (versão livre do QDAMiner).

Para o tipo de pesquisa que ora apresentamos, depois de baixar os diversos softwares em versão demonstração, fazer testes variados, análise de 
funcionalidades e de custo/benefício, optou-se pela aquisição do Nvivo, versão 10, pacote educacional, licença anual, cujo custo possibilitou aos pesquisadores fazerem a aquisição com recursos próprios. Além de ser um software poderoso e estável (como os demais que citamos), estar no mercado há muito tempo, ser consolidado e testado por pesquisadores do mundo inteiro, ele dá suporte às necessidades teóricas e metodológicas da pesquisa.

O Nvivo possui, como vantagem, quase todas as características que citamos previamente: indexação de textos, imagens, áudio e vídeo, com boa qualidade na busca e recuperação de informação. Permite ao usuário, conforme a abordagem teórica e metodológica que usa como fundamentação para o processo de análise, implementar categorias e subcategorias em diversos níveis de profundidade, fazer quadros de correlação e estratificação, correlação com outros recursos (planilhas, softwares estatísticos etc.), importar dados de formatos DOC, RTF, PDF, MPEG, MP3 e fazer a utilização integrada desses recursos, fazer anotações em partes do texto e memorandos diversos, elementos importante para o processo de pesquisa. Além disso, possui uma comunidade mundial de utilizadores para troca de experiência, métodos, recursos, técnicas e facilidades.

Como limitação do Nvivo, apesar de possuir uma ferramenta própria de transcrição que interliga o áudio ou vídeo com a parte transcrita, esse procedimento é muito trabalhoso, e ainda apresenta algumas inconsistências (bugs), sendo pouco amigável e eficaz. O processo de transcrição é mais eficiente usando ferramentas específicas para isso ou com o uso do próprio editor de texto alternando com algum reprodutor de áudio ou vídeo (opção que usamos). Outra questão que avaliamos que poderia ser melhorada são alguns aspectos da usabilidade da interface que, comparando com o que já se dispõe em outros softwares, de propósito comuns mais corriqueiros (editor de texto, planilhas etc.), poderia ser melhorado. Por fim, se é que podemos dizer que seria uma limitação, o software oferece uma infinidade de recursos e possibilidades que, por vezes, confundem o usuário iniciante, fazendo com que o tempo inicial dedicado à aprendizagem seja considerável.

A tela básica do Nvivo, na Figura 1, é composta: pela Barra superior 
(destaque em vermelho), onde se pode ter acesso às opções arquivo, início, criar, dados externos, analisar, consulta etc. Pela coluna esquerda (cor azul) se tem acesso aos arquivos fonte, 'Nós', coleções, consultas etc. Pela parte Central (cor verde) temos a visualização do item ativo no momento. No exemplo da Figura 1 vemos a codificação composta por diversos 'Nós' (nome utilizado no Nvivo para os indicadores e categorias).

Figura 1 - Tela básica do Nvivo.

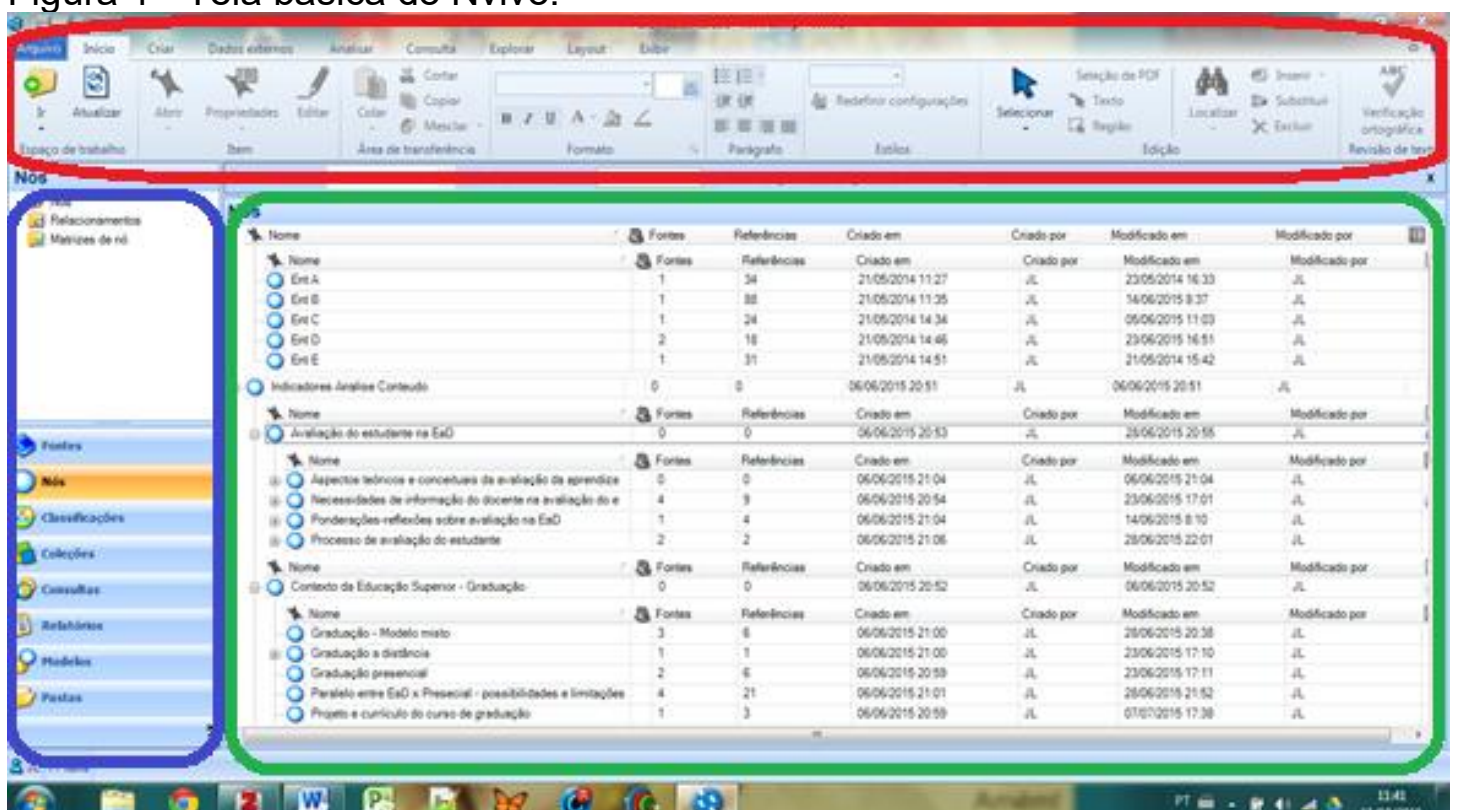

Fonte: Dos autores, a partir do Software Nvivo.

Sugerimos, para melhor entendimento do processo aqui descrito, que o leitor baixe a versão de demonstração do Software Nvivo e faça alguns testes e codificações. Diversos tutoriais estão disponíveis explicando o uso básico do Software.

\subsection{Mapas Mentais}

Os Mapas Mentais (Mind Maps) são representações que tentam mapear, externalizar, simular e se aproximar do processo cognitivo humano e das interrelações e conexões que ocorrem no cérebro.

"Representar é o ato de utilizar elementos simbólicos - palavras, figuras, 
imagens, desenhos, mímicas, esquemas, entre outros - para substituir um objeto, ideia ou um fato" (LIMA; ALVARES, 2012, p. 21).

Os Mapas Mentais são representações. A técnica foi concebida a partir da teoria de Ausubel de aprendizagem significativa (MARQUES, 2008) e estruturada por Buzan em 1970, incialmente, como uma técnica para auxiliar os estudantes a aprenderem melhor. Nos últimos anos seu interesse se ampliou para o ambiente dos negócios, apoiando o planejamento de projetos e apresentações, realização de brainstorming, com um crescimento expressivo nas áreas de engenharia, educação e mesmo pesquisa (TUCKER; ARMSTRONG; MASSAD, 2015).

Um mapa mental é uma ferramenta de planificação e de anotação de informações de forma não linear, ou seja, em forma de teia ou rede. Isto significa que a ideia principal é formalmente colocada no centro e as ideias associadas são descritas apenas com palavras-chave e ilustradas opcionalmente com imagens, ícones e cores variadas (MARQUES, 2008, p. 36).

Os Mapas Mentais surgem da percepção da importância da integração da capacidade dos dois hemisférios cerebrais nos processos de assimilação. $O$ hemisfério esquerdo seria responsável pelos aspectos racionais, processando palavras, letras, números e códigos, utilizando o processo de raciocínio lógico. O hemisfério direito lida com os aspectos emocionais, sensações, simbolismos, imagens, ritmos etc., utilizando processos mais intuitivos (MARQUES, 2008).

Nos Mapas Mentais se pode trabalhar com a essência de um conceito e com imagens, símbolos, termos e ideias relacionados a eles, favorecendo um processo criativo e não linear de organização da informação. Utilizam uma estrutura hierárquica (taxonômica) para representar uma ideia e os conceitos subjacentes, com o apoio de desenhos, textos e imagens para fazer a representação de elementos.

Buzan (1996 apud TUCKER; ARMSTRONG; MASSAD, 2015) coloca que a memória é naturalmente associativa, sendo mais fácil para o cérebro assimilar informações multimensionais, e com estímulos visuais e associações entre conceitos.

Inf. Inf., Londrina, v. 21, n. 3, p. 63 - 100, set./dez., 2016. 
Além da memorização, os Mapas Mentais favorecem os processos criativos e de organização de ideias do brainstorming (tempestade de ideias), desenvolvimento e organização de categorias, síntese de conceitos, resumo de ideias de leituras ou estudos etc.

Tucker, Armstrong e Massad (2015) colocam que as pesquisas relacionadas com os Mapas Mentais estão em estágio embrionário e exploratório. Na pesquisa realizada pelos referidos autores sobre a aplicação dos Mapas Mentais nos setores de Educação, Negócios e Governos, o brainstorming foi a utilização que ficou em primeiro lugar. Outras formas de utilização dos Mapas Mentais detectadas pela pesquisa são: Gestão de Projetos e Resolução de Problemas, utilização comum nos 3 (três) setores pesquisados; Melhoria de Processos (setor de negócios); condução de pesquisas (no setor educacional) (TUCKER; ARMSTRONG; MASSAD, 2015). Algumas pesquisas na Educação demonstram a efetividade da utilização dos Mapas Mentais no processo de aprendizagem e a equivalência na eficiência quando comparado com os processos mais tradicionais de estudo (FARRAND; HUSSAIN; HENNESSY, 2002).

Os Mapas Mentais podem ser feitos manualmente e com o uso de softwares. Na Internet existem inúmeros sítios com tutoriais sobre como fazer Mapas Mentais, que sugerimos consultar, uma vez que não é o nosso objetivo ensinar a técnica dos Mapas Mentais.

Para o processo aqui apresentado, pensou-se no uso do Mapa Mental como uma ferramenta para brainstorming, utilizando-se da plasticidade da árvore hierárquica, contendo os conceitos chaves e sucessivas subdivisões de categorias. O brainstorming apresenta-se como uma técnica que favorece o pensamento criativo, contribuindo no processo de criação de categorias e subcategorias necessários para a Análise de Conteúdo.

Existem diversos softwares de Mapas Mentais, inclusive para Smartphones, ou versão Web para construção em rede, os quais citamos: Mind Meister, Xmind, Mind Manager, Coggle, FreeMind, entre outros.

Para a presente atividade, optou-se pelo FreeMind por ser uma ferramenta acessível, gratuita (freeware), de fácil manuseio e que favorece a 
José Leonardo Oliveira Lima; Miriam Paula Manini.

Metodologia para análise de conteúdo qualitativa integrada à técnica de mapas mentais com o uso dos softwares Nvivo e Freemind

organização e reorganização dos ramos do mapa mental com facilidade e praticidade, elementos necessários no processo de organização das categorias e indicadores de análise de conteúdo.

Figura 2 - Tela do FreeMind com Mapa Mental de parte das categorias da pesquisa.

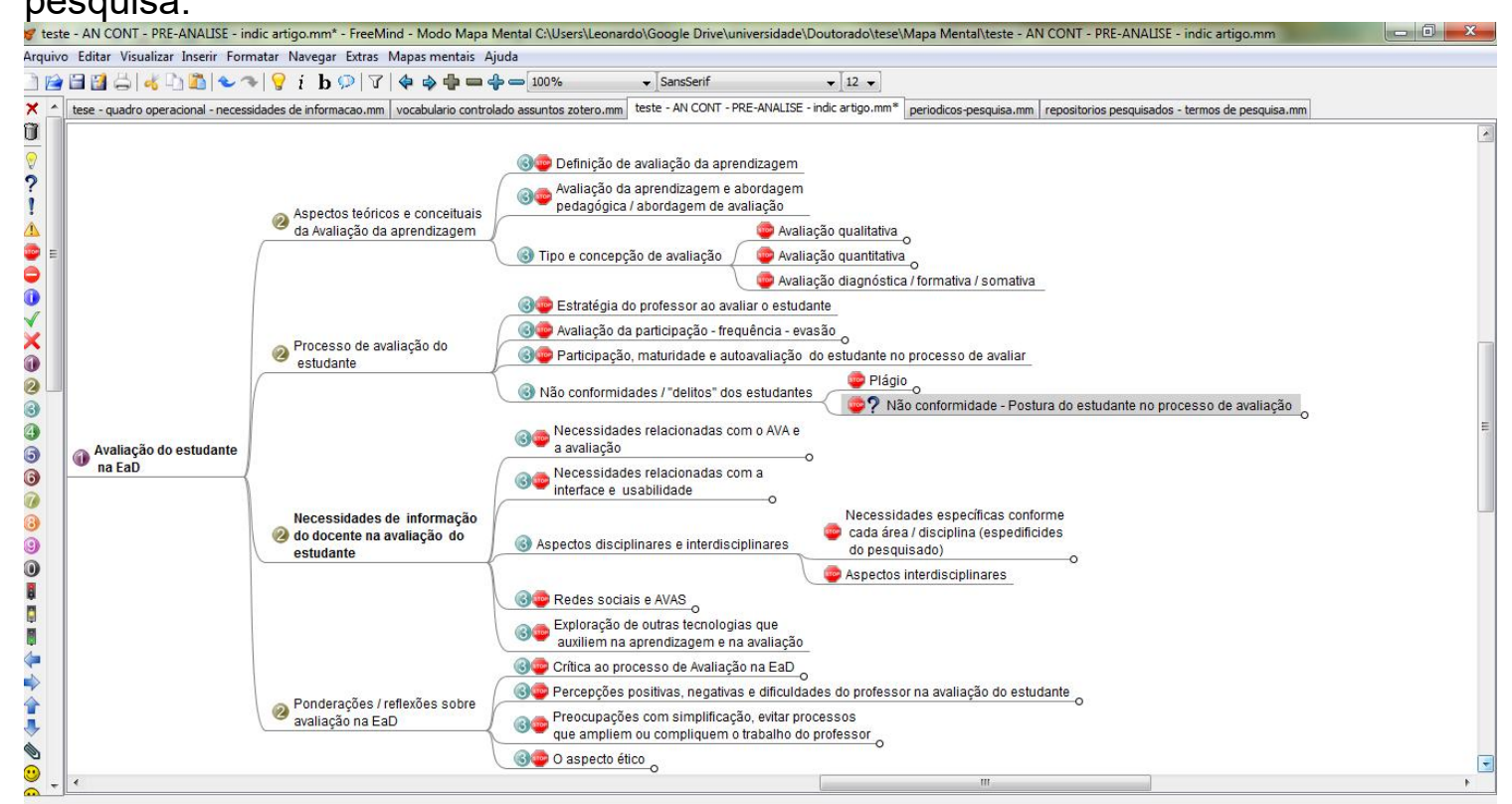

Fonte: Dos autores, a partir do Software FreeMind.

\section{METODOLOGIA}

Foram utilizadas algumas das classificações propostas por Gil (2010) e taxionomia proposta por Vergara (2009), que apresenta o tipo da pesquisa quanto aos fins e quanto aos meios. Quanto aos fins, a pesquisa foi concebida como descritiva e metodológica: descritiva porque foram estudadas e descritas as percepções dos atores foco da pesquisa; metodológica pois, o processo de pesquisa proposto e a metodologia (que ora apresentamos) poderão servir de contribuição para outros estudos de usuários com abordagens qualitativas na CI. Quanto aos meios, a pesquisa foi bibliográfica e de campo.

Inf. Inf., Londrina, v. 21, n. 3, p. 63 - 100, set./dez., 2016. 
A amostra foi não probabilística, utilizando os critérios de conveniência ${ }^{1}$. O processo de escolha dos entrevistados seguiu o critério da experiência do entrevistado e nível de expertise em âmbito nacional. Foram escolhidos 05 professores especialistas (notório saber), com vasta experiência acadêmica na Educação Superior, Educação a Distância e acompanhamento da aprendizagem por meio de Ambientes Virtuais de Aprendizagem. Os especialistas entrevistados têm entre 14 e 34 anos de experiência em Educação Superior (28 anos na média aritmética). O tempo de término do doutorado é de 9 a 27 anos (17 anos na média).

As entrevistas foram abertas, porém orientadas por uma pauta (Apêndice A), para suscitar a discussão sobre a temática e o contexto, estimular o diálogo com o entrevistador e fazer aflorar os assuntos e a problematização relacionados com o problema de pesquisa, não se prendendo ao roteiro da pauta. As entrevistas tiveram o áudio gravado com dois dispositivos de gravação (redundância) e duração entre 1 h10 e 2h cada.

À medida que as entrevistas foram sendo realizadas, o entrevistador anotava em um diário de bordo (memorando) as especificidades, peculiaridades etc. O processo era constantemente reavaliado e aprimorado para obter as informações mais pertinentes ao objeto da pesquisa, com o cuidado de não modificar o foco inicial e os temas a serem explorados, porém com a flexibilidade para perceber a profundidade do conteúdo bem como as questões latentes ou ainda não elaboradas racionalmente pelos especialistas entrevistados, elementos importantes que afloram em uma entrevista aberta.

Foram seguidas estratégias de transcrição e precisão conforme orientações de Gibbs (2009, p. 28-37). A transcrição das entrevistas foi literal, com a fala coloquial. Para anotar os elementos não verbais se utilizou como referência o quadro que consta no Apêndice $B$, cujas características foram adaptadas e ampliadas pelos autores para auxiliar no processo de análise

\footnotetext{
1 Patton (2002 apud FLICK, 2009b, p. 125) utiliza a terminologia "critério da conveniência", que se refere "à seleção daqueles casos mais acessíveis sob determinadas condições"
}

Inf. Inf., Londrina, v. 21, n. 3, p. 63 - 100, set./dez., 2016. 
conforme é discutido por Bardin (2011), Flick (2009b) e Gibbs (2009).

A transcrição foi realizada utilizando o Editor de Textos Microsoft Word e o reprodutor (player) de áudio e vídeo Apple Quick Time. Na transcrição também se procedeu à anonimização, sendo que foi ocultada toda e qualquer referência que pudesse favorecer a identificação do entrevistado ou da instituição em que trabalha.

Para o tratamento das entrevistas, utilizou-se o processo de Análise de Conteúdo Qualitativa apresentado por Bardin (2011), Krippendorff (2013) e Mayring (2014) e alguns pressupostos metodológicos apresentados por Gibbs (2009) e Flick (2009b), com algumas adaptações necessárias para a pesquisa.

Na Análise de Conteúdo, optou-se pelo procedimento de exploração para encontrar os indicadores e realizar a organização em categorias. A unidade básica de registro foi o "tema".

O processo de Análise de Conteúdo foi realizado utilizando o software Nvivo 10 de apoio a Análise de Dados Qualitativos (Qualitative Data Analysis) e a técnica dos Mapas Mentais com o uso do Software FreeMind.

Destaca-se que o processo de pesquisa foi realizado de maneira circular e interativa, característica das abordagens qualitativas, conforme já explicitado.

\section{PROCESSO DE ANÁLISE DE CONTEÚDO QUALITATIVA COM O SUPORTE DOS SOFTWARES NVIVO E FREEMIND}

Os textos das entrevistas, já transcritos e devidamente revisados no Editor de Textos, foram importados para o Software Nvivo.

A partir das entrevistas já armazenadas no Nvivo, realizou-se o primeiro processo de codificação. Toda codificação no Nvivo (ou seja, indicador, categoria etc.) tem o nome de "Nó". O discurso de cada entrevistado foi codificado como um Nó, cada qual identificado como "Ent A", "Ent B" e assim sucessivamente, contendo somente o conteúdo da fala do entrevistado, separando as perguntas ou intervenções do entrevistador.

Durante a fase da pré-análise, optou-se, primeiramente, por criar uma nuvem de palavras (recurso do Nvivo) com as falas individuais de cada 
entrevistado, para se fazer a análise dos assuntos mais abordados por cada um e obter os primeiros insights do discurso individual de cada entrevistado. Também se processou outra nuvem de palavras com os termos gerais de todos os entrevistados (Figura 3). Também foram analisadas as tabelas quantitativas de frequências geradas pelo software, tanto para cada entrevistado como para a totalidade. As nuvens de palavras e as tabelas quantitativas possibilitaram levantar algumas suposições e insights que foram anotados na opção "Memorandos" do Nvivo, para o momento da análise de conteúdo temática e de enunciação.

Figura 3 - Nuvens de Palavras de Todos os Entrevistados.

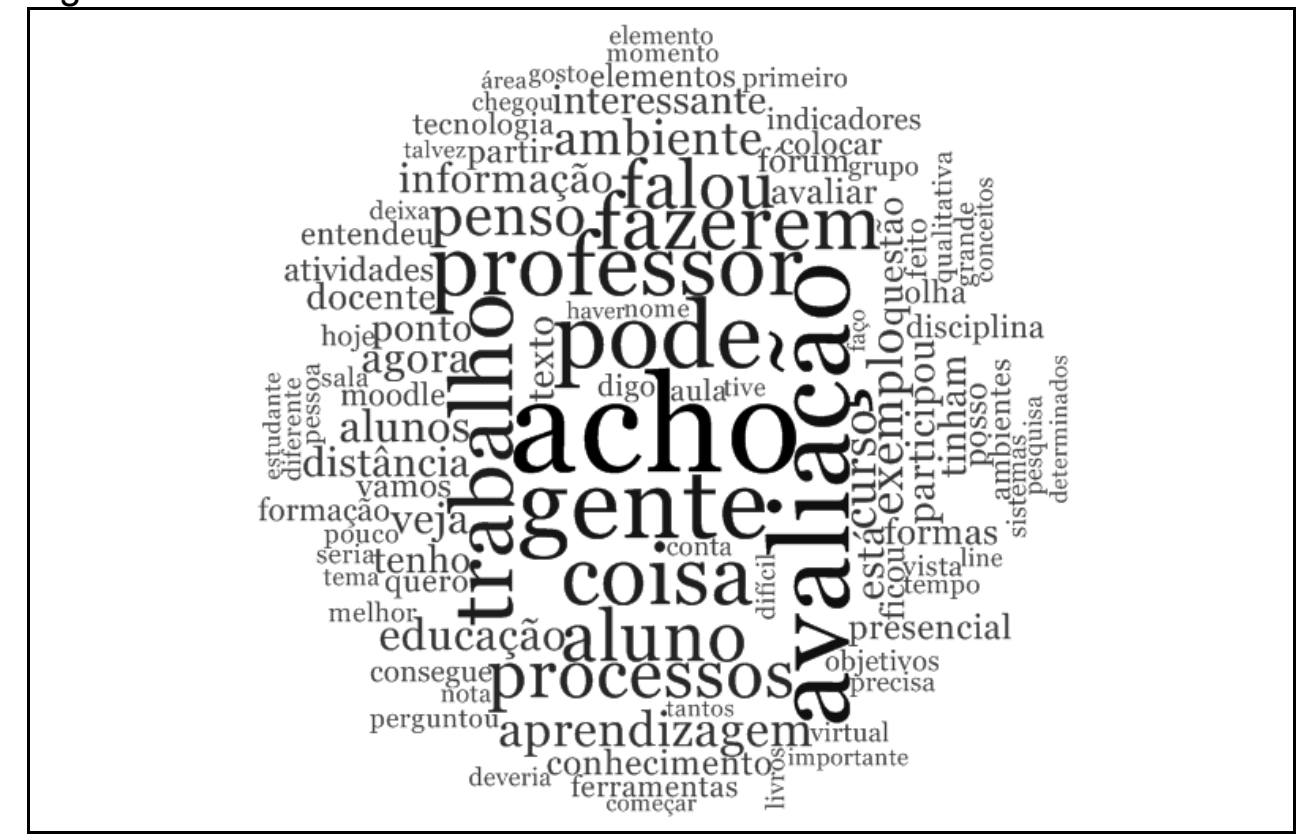

Fonte: Dos autores, a partir do Software Nvivo.

Da observação da nuvem de palavras e tabelas de frequência, realizouse um primeiro brainstorming no Software FreeMind, para não perder as possíveis ideias. Essa primeira versão teve um processo livre de proposição de indicadores como sugere a técnica do brainstorming.

A partir do problema de pesquisa - "Quais são as necessidades de informação dos docentes na avaliação de estudantes de graduação a distância, mediada por Ambientes Virtuais de Aprendizagem (AVA)?" - foram propostas 
as dimensões superiores que deveriam ser a base do processo de análise, que foram lançados no FreeMind. As dimensões que propusemos inicialmente, que viriam a ser aprimoradas posteriormente, foram "Processo de avaliação dos estudantes na EaD”, "necessidades de informação dos docentes na avaliação", "Ambientes Virtuais de Aprendizagem e AVA".

Os indicadores inicialmente propostos tiveram uma primeira organização em categorias e subcategorias subordinadas às dimensões previamente citadas no software FreeMind, porém ainda sem muito rigor e crítica.

Na sequência, iniciou-se a leitura exploratória de cada entrevista, com os apontamentos de observações, insights ou suposições (que denominamos "Memorandos da fase exploratória" e foram armazenados no Nvivo) que poderiam ser úteis no processo final de análise e inferência.

Como a unidade de registro foi o tema, na medida que se realizava a leitura exploratória, os índices (conteúdos) que iam aparecendo e sendo identificados como um indicador (tema ou assunto) tinham o indicador lançado no Mapa Mental em construção no FreeMind (novamente conforme o processo de brainstorming, ainda sem muita crítica, deixando aflorar o processo criativo).

Ao término da leitura exploratória de cada entrevistado, com o brainstorming de indicadores lançados no FreeMind, realizou-se o processo de avaliação da etapa, sendo os indicadores criticados, os que eram redundantes ou desnecessários excluídos ou renomeados, sendo organizados e reorganizados em categorias e subcategorias subordinadas às dimensões extraídas do problema de pesquisa. Assim se procedeu com todas as entrevistas na leitura exploratória.

Ao término das leituras exploratórias, com a primeira árvore de dimensões, categorias, subcategorias e indicadores, realizou-se, novamente, diversas críticas aos ramos do mapa mental, retornando sempre ao problema de pesquisa, ao referencial teórico, às suposições iniciais para análises e modificações do Mapa Mental até chegar à primeira árvore com os indicadores e categorias que seria utilizada na codificação de fato.

A partir do Mapa Mental (vide exemplo na Figura 2), com as dimensões, categorias, subcategorias e indicadores, realizou-se o lançamento e 
organização dos Nós e suas subdivisões no Nvivo. No Nvivo tudo é chamado de Nó, pois trabalha com o conceito de árvore hierárquica, cujas raízes podem ser entendidas como os Nós pais (raízes superiores) e filhos (raízes subordinadas), conforme Figura 4.

Figura 4 - Árvore de Nós do Nvivo.

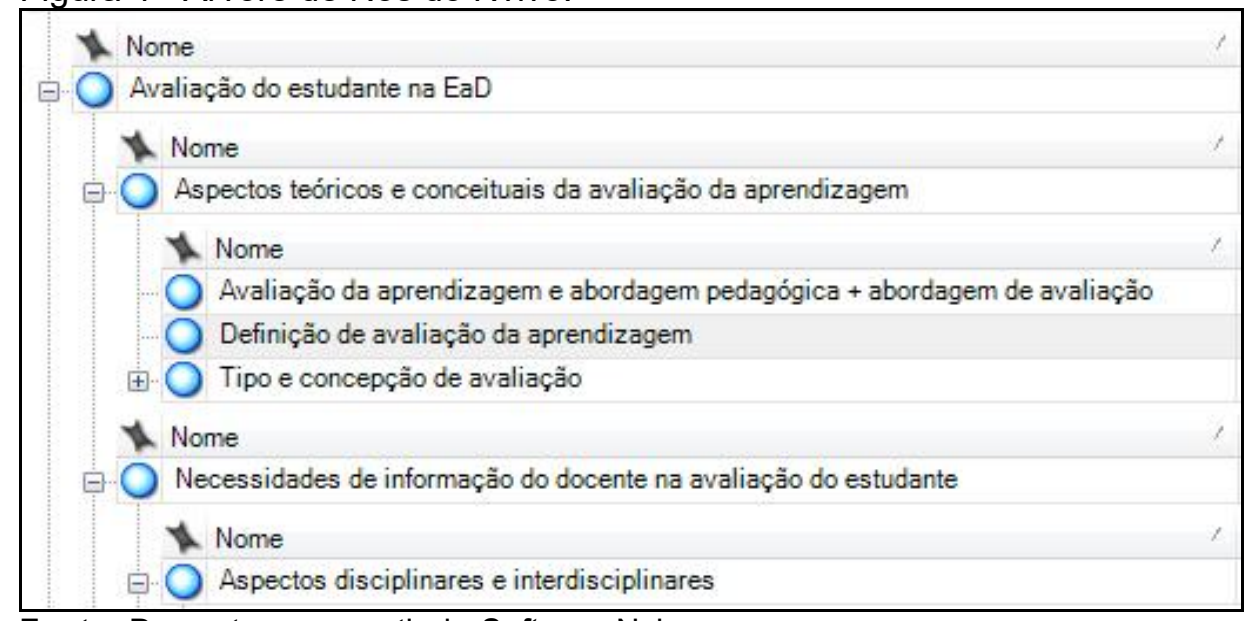

Fonte: Dos autores, a partir do Software Nvivo.

O manuseio da árvore hierárquica no NVIVO é trabalhoso, e qualquer descuido pode fazer com que um Nó (e toda sua codificação) seja colocado como subordinado a outro Nó ou apagado, sem que o usuário perceba o erro. Portanto, a manipulação da árvore de Nós no Nvivo requer muito cuidado e não favorece a organização e reorganização ágil que se faz necessário quando dos processos criativos de reorganização de ideias de um brainstorming para a criação de categorias.

À medida que os Nós (indicadores) são codificados, com a visualização e validação dos indicadores inseridos no contexto dos discursos dos entrevistados, percebe-se a necessidade de aprimoramento das categorias. Com um simples clicar e arrastar, realiza-se, primeiramente, os testes e validações no Mapa Mental do FreeMind. Validado e finalizado o reajuste nas categorias, aí então é que se parte para a atualização dos Nós no Nvivo.

Esse processo, em uma primeira análise, pode parecer redundante, pois exige a mudança no FreeMind e depois no Nvivo; porém, a forma visual como o FreeMind apresenta os dados facilita uma melhor visualização de toda a 
árvore do Mapa Mental e seus ramos de dimensões, categorias e subcategorias (Figura 2), facilitando a reorganização com confiabilidade, diferentemente da apresentação no Nvivo (Figura 4), que tem uma forma de apresentação que dificulta a visualização de todos os Nós.

Durante a codificação, algumas organizações das categorias, indicadores e seus escopos passam a ser criticadas e questionadas. Para não se perder as ideias e insights que surgem na etapa de codificação, essas questões são anotadas no software como "memorandos de codificação". Isso permite que o pesquisador, ao final da codificação de cada entrevista, possa retornar ao Mapa Mental, analisar a pertinência da mudança, reagrupamento etc. A cada iteração de codificação, esse processo se repete, favorecendo o aprimoramento do quadro de indicadores e categorias. Finalizada a etapa a codificação, ainda se procede a uma última análise das categorias e indicadores, o que favorece outros reagrupamentos e ajustes finais.

Figura 5 - Árvore de Nós (esquerda) e conteúdos (direita).

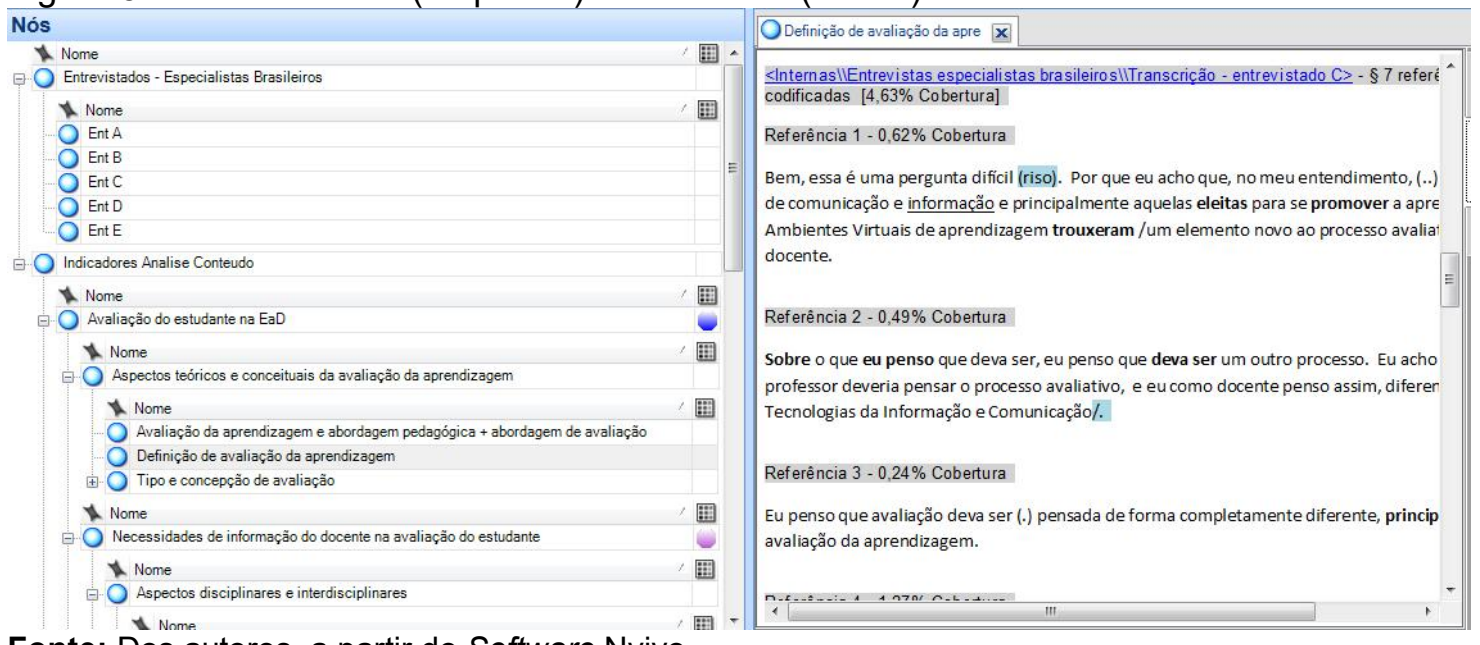

Fonte: Dos autores, a partir do Software Nvivo.

Com os indicadores organizados (os Nós codificados com o seu conteúdo ou, usando a nomenclatura da $\mathrm{AC}$, os indicadores contendo os seus devidos índices), inicia-se o processo de análise de conteúdo de todas as entrevistas realizadas e os Nós codificados, observando o critério de exaustividade por tema (unidade de registro), usando os indicadores previamente organizados.

Inf. Inf., Londrina, v. 21, n. 3, p. 63 - 100, set./dez., 2016. 
O Nvivo permite gerar relatórios com os conteúdos dos Nós e, por intermédio desses relatórios, é possível acessar os conteúdos dos Nós (Figura 5).

A partir a árvore de Nós, no Nvivo se pode emitir relatórios em editor de texto do conteúdo de cada indicador, bem como se pode fazer a visualização na tela das ocorrências e iniciar a análise, interpretação e inferências. Por exemplo: na Figura 5 (coluna esquerda), ao clicar duas vezes o Nó (indicador) "Definição de avaliação da aprendizagem" apareceram na coluna esquerda todos os conteúdos (índices) codificados no Nó.

A partir das ferramentas de relatórios dos conteúdos dos Nós, das pesquisas e estratificações possíveis com o software, vai se buscando compreender e responder às diversas perguntas do pesquisador sobre 0 conteúdo codificado. É nesse momento que se busca os memorandos e os insights anotados durante a pré-análise, codificação etc., que podem auxiliar na análise; as consultas com os operadores booleanos (e, ou, não) são realizadas, utilizando os inúmeros recursos de busca e recuperação da informação do software para apoiar o pesquisador nos processos cognitivos de análise.

$\mathrm{Na}$ análise temática, realizou-se, portanto, a justaposição das falas, organizadas nos indicadores e categorias, levantando algumas frequências para apresentar uma síntese do que é concordante, discordante, inovador etc. nas diversas falas. Optou-se por fazer um texto apresentando os conteúdos seguindo a lógica do Mapa Mental, sendo que as dimensões e categorias se transformaram nos tópicos e sub-tópicos do texto do relatório da pesquisa, respectivamente, e as subcategorias e indicadores nos assuntos ou tópicos frasais que foram sintetizados e compuseram os parágrafos, fazendo ligação com algumas citações de falas dos entrevistados.

Como a análise de conteúdo foi de entrevistas com especialistas, compreendeu-se que a análise deveria ir além da colocação de abordagens das temáticas que ocorreram com maior frequência ou elementos que são comuns nas falas de cada especialista e, portanto, mais evidentes e já percebidos como necessidades na área.

Buscou-se também encontrar o singular de cada fala dos entrevistados, 
usando alguns elementos da análise de enunciação, como também sugere Bardin (2011), pois assim se teve acesso aos aspectos inovadores das necessidades de informação para além do que já existe, do que é comum e percebido pelos especialistas e seus pares, procurando perceber alguns aspectos latentes sobre a temática, que afloraram na fala dos entrevistados.

$\mathrm{Na}$ análise de enunciação, com o olhar processual em cima da fala de cada entrevistado e os memorandos feitos durante a pré-análise, retornou-se às nuvens de palavras e tabelas de frequência da fala de cada entrevistado, os indicadores (Nós) mais frequentes; procedeu-se à análise do conteúdo usando os relatórios estratificados que o software favorece, para se chegar à síntese e aos elementos principais do discurso de cada entrevistado. Buscou-se compreender o discurso processualmente e as contribuições adicionais de cada entrevistado; contudo, não foram aprofundados aspectos referentes à manifestação psicológica, afloração do inconsciente etc., como Bardin (2011) propõe, por não se tratar de elementos da nossa área de domínio e interesse.

Seguiu-se, portanto, um processo híbrido para a Análise de Conteúdo Qualitativa, abrangendo a análise temática e a análise de enunciação, tentando apreender a totalidade dos aspectos importantes abordados (e os silêncios) dos entrevistados relacionados com o problema de pesquisa, bem como o singular da exposição de cada entrevistado, indo além do manifesto, percebendo alguns aspectos do latente que seriam importantes para a pesquisa.

Sintetizando, depois de tudo codificado, organizado em categorias e subcategorias, o processo de busca e recuperação da informação, de busca das citações e falas dos entrevistados, de inferência, de interpretação e de generalização das fontes ficam mais facilitados para a análise de conteúdo qualitativa, ficando ainda o árduo trabalho intelectual de redação final do relatório de síntese e diálogo entre os diversos elementos encontrados na pesquisa.

\section{CONCLUSÃO}

Nas Ciências Sociais e Ciências Sociais Aplicadas, as discussões sobre 
a metodologia e epistemologia nas pesquisas com abordagens qualitativas são profícuas e podem trazer contribuições importantes para o processo na $\mathrm{Cl}$.

Apresentou-se nesse artigo algumas reflexões envolvendo o diálogo interdisciplinar necessário da Ciência da Informação, do campo de Estudos de Usuários com os referenciais teóricos e epistemológicos das áreas das Ciências Sociais e Sociais Aplicadas para o aprimoramento dos processos de pesquisa com o apoio de softwares de análise qualitativa e dos mapas mentais, teórica e metodologicamente fundamentados.

São poucos os trabalhos que fazem a correlação entre o referencial teórico, o processo metodológico de análise de conteúdo qualitativo e o percurso empreendido. Se considerarmos a utilização dos softwares de apoio ao processo, essa correlação é ainda menor (KAEFER; ROPER; SINHA, 2015). Existe uma tendência de o foco ser somente do uso dos softwares ou dos recursos, sem fazer a devida correlação com a teoria que fundamentam o processo. O processo de Análise de Conteúdo Qualitativa aqui descrito tentou preencher um pouco dessa lacuna, além de demonstrar um percurso viável que pode servir de apoio ou ser adaptado para outras pesquisas qualitativas que se utilizam de entrevistas abertas no campo de estudos de usuários.

Com relação à utilização da técnica e do software de Mapas Mentais para auxiliar na proposição dos indicadores e categorias para a análise do conteúdo, percebeu-se um grande potencial, sendo que a ferramenta, devido aos aspectos visuais e a facilidade nos rearranjos das categorias e subcategorias, facilita o processo criativo do brainstorming e de reorganização das ideias nas diversas fases do processo de Análise de Conteúdo Qualitativa, até chegar em um nível de categorias, subcategorias e indicadores otimizados.

Vale observar que o processo ACQ apresentado nesse artigo pode, inclusive, ser facilmente adaptado e utilizado com outros softwares, conforme as necessidades e possibilidades de cada pesquisa, não se restringindo ao Nvivo e FreeMind.

Como limitação do presente estudo, apresentamos a amostra reduzida de entrevistados, sendo que, para a ampliação e o aprimoramento do processo, recomenda-se como futuros estudos: a utilização de um quantitativo 
maior de entrevistados; mais pessoas/pesquisadores processando a pesquisa colaborativamente, para verificação do funcionamento do processo e seu aprimoramento. Outra sugestão para futuros estudos seria e validação do processo com pesquisas semiestruturadas, estruturadas, questões abertas, bem como com outros processos de análise de conteúdos não textuais (imagens fixas, imagens em movimento etc.).

Por fim, como sugestão para o aprimoramento dos QDAS, seria interessante a implementação de um módulo de Mapa Mental de manuseio simplificado, para a criação, organização e reorganização das categorias e subcategorias, que já reorganizariam os dados codificados, diferentemente das árvores hierárquicas dos QDAS, que, no geral, requerem muito cuidado no manuseio e oferecem relativa complexidade e dificuldade na visualização sistêmica das categorias.

\section{REFERÊNCIAS}

BARDIN, Laurence. Análise de conteúdo. São Paulo: Edições 70, 2011.

BATES, Márcia J. The invisible substrate of information science. Journal of the American Society for Information Science, New York, v. 50, n. 12, p. 10431050, 1999.

CAPURRO, Rafael; HJORLAND, Birger. O conceito de informação. O conceito de informação. Perspectivas em Ciência da Informação, Belo Horizonte, v. 12, n. 1, p. 148-207, jan. 2007.

CIBANGU, Sylvain K. A memo of qualitative research for information science: toward theory construction. Journal of Documentation, London, v. 69, n. 2, p. 194-213, 2013. Disponível em:

<http://www.emeraldinsight.com/10.1108/00220411311300048>. Acesso em: 12 nov. 2015.

DELLAGNELO, Eloise Helena Livramento; SILVA, Rosimeri Carvalho. Análise de conteúdo e sua aplicação em pesquisa na administração. In: VIEIRA, Marcelo Milano Falcão; ZOUAIN, Deborah Moraes (Org.). Pesquisa qualitativa em administração: teoria e prática. Rio de Janeiro: FGV, 2005. 
DEMO, Pedro. Metodologia científica em ciências sociais. 3. ed. São Paulo: Atlas, 1995.

FARRAND, Paul; HUSSAIN, Fearzana; HENNESSY, Enid. The efficacy of the "mind map" study technique. Medical Education, v. 36, n. 5, p. 426-431.

Disponível em:

<http://onlinelibrarywileycom.ez54.periodicoscapes.gov.br/doi/10.1046/j.1365-

2923.2002.01205.x/abstract>. Acesso em: 8 out. 2015.

FIDEL, Raya. Are we there yet? Mixed methods research in library and information science. Library \& Information Science Research, Seattle, v. 30, n. 4, p. 265-272, dez. 2008. Disponível em:

<http://linkinghub.elsevier.com/retrieve/pii/S074081880800073X>. Acesso em: 01 nov. 2015.

FLICK, Uwe. Desenho da pesquisa qualitativa. Porto Alegre: Bookman: Artmed, 2009a.

. Introdução à pesquisa qualitativa. 3. ed. Porto Alegre: Artmed: Bookman, 2009b.

GIBBS, Graham R. Análise de dados qualitativos. Porto Alegre: Kookman: Artmed, 2009.

GIBBS, Graham R.; FRIESE, Susanne; MANGABEIRA, Wilma C. The use of new technology in qualitative research. Introduction to issue 3 (2) of FQS.

Forum: Qualitative Sozialforschung, v. 3, n. 2, 31 maio 2002. Disponível em: $<$ http://www.qualitative-research.net/index.php/fqs/article/view/847>. Acesso em: 5 nov. 2015.

GIL, Antonio Carlos. Como elaborar projetos de pesquisa. 5. ed. São Paulo: Atlas, 2010.

HJORLAND, Birger. Library and information science and the philosophy of science. Journal of Documentation, London, v. 61, n. 1, p. 05-10, $01 \mathrm{fev}$. 2005. Disponível em: <http://www.emeraldinsight.com/journals.htm?issn=00220418 \& volume $=61 \&$ issue $=1$ \&articleid $=1465004 \&$ show $=$ abstract $>$. Acesso em: 12 nov. 2015.

KAEFER, Florian; ROPER, Juliet; SINHA, Paresha. A Software-assisted qualitative content analysis of news articles: example and reflections. Forum: Qualitative Social Research, v. 16, n. 2, maio 2015. Disponível em: $<$ http://www.qualitative-research.net/index.php/fqs/article/view/2123>. Acesso em: 5 nov. 2015. 
KRIPPENDORFF, Klaus. Content analysis: an introduction to its methodology. 3. ed. Los Angele: California: SAGE, 2013.

LE COADIC, Yves-François. A ciência da informação. 2. ed. Brasília: Briquet de Lemos, 2004.

LEWINS, Ann; SILVER, Christina. Choosing a CAQDAS package. Disponível em:

<http://www.surrey.ac.uk/sociology/research/researchcentres/caqdas/files/2009 ChoosingaCAQDASPackage.pdf>. Acesso em: 12 nov. 2015.

Using software in qualitative research: a step-by-step guide. 2. ed. London: SAGE, 2014.

LIMA, José Leonardo Oliveira; ALVARES, Lillian. Organização e representação da informação e do conhecimento. In: ALVARES, Lillian et al. (Org.).

Organização da informação e do conhecimento: conceitos, subsídios interdisciplinares e aplicações. São Paulo: B4, 2012. p. 21-48.

LINCOLN, Yvonna S.; GUBA, Egon G. Controvérsias paradigmáticas, contradições e confluências emergentes. In: DENZIN, Norman K.; LINCOLN, Yvonna. S. (Org.). O planejamento da pesquisa qualitativa: teorias e abordagens. 2. ed. Porto Alegre: Artmed: Bookman, 2006. p. 169-192.

MARQUES, Antonio Manuel de Miranda. Utilização pedagógica de mapas mentais e de mapas conceptuais. 2008. 153 f. Dissertação (Mestrado em Expressão Gráfica, Cor e Imagem) - Universidade Aberta de Portugal, Lisboa, 2008. Disponível em: <http://repositorioaberto.uab.pt/handle/10400.2/1259>. Acesso em: 16 nov. 2015.

MAYRING, Philipp. Qualitative content analysis: theoretical foundation, basic procedures and software solution. Klagenfurt, Austria: GESIS/Leibniz-Institut, 2014. Disponível em: <http://nbn-resolving.de/urn:nbn:de:0168-ssoar-395173>. Acesso em: 08 nov. 2015.

MOORE, Michael. G.; KEARSLEY, Greg. Educação a distância: uma visão integrada. São Paulo: Thomson Learning, 2007.

SARACEVIC, Tefko. A natureza interdisciplinar da Ciência da Informação.

Ciência da Informação, Brasília, v. 24, n. 1, 1995.

. Ciência da informação: origem, evolução e relações. Perspectivas em Ciência da Informação, Belo Horizonte, v. 1, n. 1, p. 41-62, 1996.

SILVA, D. G. D. Análise sobre o uso dos relatórios de atividades do Moodle no acompanhamento do processo de aprendizagem de alunos em cursos de graduação. 2011. Dissertação (Mestrado em Educação) Universidade Federal do Mato Grosso, Cuiabá, 2011. Disponível em: 
José Leonardo Oliveira Lima; Miriam Paula Manini.

Metodologia para análise de conteúdo qualitativa integrada à técnica de mapas mentais com o uso dos softwares Nvivo e Freemind

<www.ie.ufmt.br/ppge/dissertacoes/index.php?op=download\&id=303>. Acesso em: 01 nov. 2015.

\title{
Title
}

Methodology for Qualitative Content Analysis with the technique of Mind Maps using Nvivo and FreeMind softwares

\begin{abstract}
Introduction: In a survey it is not enough choosing tools, resources and procedures. It is important to understand the method beyond the technics and their relationship with philosophy, epistemology and methodology.

Objective: To discuss theoretical and methodological concerns on Qualitative Research in Information Science and the process of Qualitative Content Analysis (QCA) at User Studies field and to show a followed path of QCA integrated with Mind Maps technic for developing categories and indicators, by using Qualitative Data Analysis Software (QDAS) and Mind Maps designing tools.

Methodology: The research was descriptive, methodological, bibliographical and fieldwork conducted with open interviews that were processed using the QCA method with the support of QDAS Nvivo and FreeMind Software for Mind Map design.

Results: It is shown the theory of qualitative research and QCA and a methodological path of QCA by using techniques and software mentioned above.

Conclusions: When it comes to qualitative researches, the theoretical framework suggests the need of more dialogue among Information Science and other disciplines. The process of QCA evidenced: a viable path that might help further related investigations using the QDAS; the contribution of Mind Maps and their design softwares to develop the indicators and categories of QCA.
\end{abstract}

Keywords: Research methods. Content analysis. Qualitative analysis. User studies. Computer programs.

\section{Titulo}

Metodología para el Análisis Cualitativo de Contenido integrado con la técnica de Mapas Mentales utilizando los softwares Nvivo y FreeMind

\section{Resumen}

Introducción: En una encuesta no sólo es suficientes elegir las herramientas, recursos y procedimientos. Es importante entender el método más allá de las técnicas y su relación con la filosofía, epistemología y metodología.

Objetivo: Presentar las reflexiones teóricas y metodológicas sobre la investigación cualitativa en Ciencias de la Información y el proceso de Análisis Cualitativo de Contenido (ACC) en el campo de los Estudios de Usuarios y mostrar el camino seguido de ACC integrado a la técnica de mapas mentales para el desarrollo de las categorías e indicadores, con el uso de softwares de apoyo para el análisis de datos cualitativos (QDAS) y de diseño de los mapas mentales.

Inf. Inf., Londrina, v. 21, n. 3, p. 63 - 100, set./dez., 2016. 
Metodología: La investigación fue descriptiva, metodológico, bibliográfica y de campo con entrevistas abiertas cuyo tratamiento fue por el método de ACQ con el apoyo de QDAS Nvivo y del software FreeMind.

Resultados: Se demuestra la teoría de la investigación cualitativa y la ACC y una ruta metodológica de ACC utilizando las técnicas y los softwares mencionados de una manera integrada.

Conclusiones: En las investigaciones cualitativas, el marco teórico sugiere la necesidad de un mayor diálogo entre la Ciencia de la Información y otras disciplinas. El proceso de ACC evidencia: un camino viable que podría ayudar otras investigaciones utilizando los QDAS; la contribución de los Mapas Mentales y sus softwares de diseño para el desarrollo de los indicadores y categorías de ACC.

Palabras clave: Métodos de investigación. Análisis de contenido. Análisis cualitativo. Estudios de usuarios. Programas de ordenador.

\section{APÊNDICE A - Entrevista Aberta - Orientada por Pauta} entrevista

- Agradecimento, apresentação do tema e autorização para gravação da

- Apresentação Pessoal

- Apresentação das especificidades da entrevista a $1 \mathrm{~h} 30 \mathrm{~m}$.

O tempo de desenvolvimento da entrevista será de aproximadamente $1 \mathrm{~h}$

A entrevista será usada apenas para fins acadêmicos, garantindo também critérios de anonimato, caso seja de sua vontade. Peço a sua autorização para gravar a entrevista. Caso tenha alguma coisa que, durante a entrevista, você não queira que seja publicado ou mesmo transcrito, pode manifestar-se e a sua vontade será respeitada. Você autoriza e concorda com a gravação da entrevista? Existe alguma restrição prévia que você gostaria de manifestar?

- Apresentação do problema da pesquisa, a contextualização e a ótica de análise

- Apresentação do objetivo da entrevista

A entrevista que realizaremos será aberta, orientada por uma pauta. As perguntas que farei são apenas elementos para orientar e fomentar o diálogo e a discussão sobre a temática. Inclusive, sinta-se à vontade para discorrer sobre outros aspectos ou ampliar o escopo das perguntas feitas.

O nosso objetivo com essa entrevista é ampliar a problemática em questão com a ótica de especialistas em processos de educação a distância e avaliação, coletar experiências e dificuldades no processo de avaliação, levantar necessidades percebidas e latentes que possam colher a percepção crítica sobre a problemática que envolve a avaliação na educação a distância por intermédio dos Ambientes Virtuais de Aprendizagem.

\section{Pauta da entrevista:}

O que você entende por avaliação da aprendizagem quando se pensa 
nos processos de Educação a Distância e nos Ambientes Virtuais de Aprendizagem (AVAs)?

Você percebe que a avaliação do estudante poderia ser mais efetiva na educação a distância usando os AVAs? Como isso poderia ser melhorado?

Qual(is) ambiente(s) virtual(ais) de aprendizagem você usa, usou, avaliou ou acompanhou o uso? Você já fez uso de quais ferramentas ou recursos disponibilizados pelos ambientes virtuais?

Como você avalia os ambientes virtuais no processo de avaliação da aprendizagem e as ferramentas disponibilizadas por eles?

Quais as dificuldades na avaliação de estudantes de cursos a distância mediados por AVAs?

Como você acha que a tecnologia pode ajudar nesse processo de avaliação de alunos de um curso a distância?

$\mathrm{O}$ que você acha que existe hoje nos ambientes virtuais que poderia ser melhorado para o docente no processo de avaliação do aluno?

Quais outros aspectos relacionados à avaliação da aprendizagem você gostaria de abordar e que não foi contemplado nas perguntas feitas? Sinta-se à vontade para discorrer sobre o que achar necessário.

Quais autores e trabalhos você conhece relacionados à temática e sugere que deveriam compor o referencial teórico desta Tese?

\section{APÊNDICE B - Simbologia usada na transcrição}

Quadro 1 - Simbologia usada na transcrição

( ) - Pontos entre parênteses significam silêncio - pausa no discurso (cada ponto é aproximadamente 1 segundo). Exemplo: (..) \{dois segundos de pausa\}

(palavra, termo, expressão) - Quando a palavra é repetida, efeitos onomatopaicos, marcadores de discursos, termos coloquiais etc. Ex.: (de de um um), (né) (ok) (hunrum)

- Dois pontos seguidos, depois de uma palavra ou frase: interrupção da fala, corte na sequência da ideia ou interrupção pelo interlocutor. Dois pontos seguidos antes de uma palavra ou frase, aparte, interrupção do interlocutor. Ex: "Eu (pens..) meditava"; "- Ent A: A tecnologia.. - Pesq:..nesse caso você quer dizer computador.. - Ent: Sim, sim”.

(???) - Palavra, expressão ou frase que, depois de reiteradas vezes, não foi possível compreender o significado para transcrever.

Negrito - ênfase na fala, fala mais expressiva, entonação mais forte do que o normal da pessoa que fala.

Sublinhado - Menor entonação na fala, menos convicção, fala menos expressiva do que o normal da pessoa que fala.

Itálico - Palavras que sofrem alguma ação específica que é apresentada em algum comentário entre colchetes \{\} . Ex: \{o entrevistado fala e ri ao mesmo tempo\} Isso é algo que acontece, mas faz parte da profissão.

\{\} - Comentários, percepções, considerações, observações etc. do pesquisador durante a transcrição. Ex.: \{o entrevistado limpa a garganta\}. No processo de anonimização, muitos comentários e percepções do autor foram ocultados, ficando somente acessíveis ao autor da

Inf. Inf., Londrina, v. 21, n. 3, p. 63 - 100, set./dez., 2016. 
José Leonardo Oliveira Lima; Miriam Paula Manini.

Metodologia para análise de conteúdo qualitativa integrada à técnica de mapas mentais com o uso dos softwares Nvivo e Freemind

tese.

[ ] - Aparte ou fala do interlocutor, durante a fala da pessoa que está com o discurso no momento.

/ / - velocidade de fala mais rápida do que o normal do entrevistado. Ex.: /fala rápida/

$\backslash \backslash$ - velocidade de fala mais lenta do que o normal do entrevistado. Ex.: Ifala lental

Fonte: Adaptado e ampliado pelos autores a partir das versões propostas por Arksey e Knight (1999), Silverman (1997 (apud GIBBS 2009, p. 31-32) e Flick (2009b, p. 271-272).

Recebido em: 10.04 .2016

Aceito em: 18.11.2016

Inf. Inf., Londrina, v. 21, n. 3, p. 63 - 100, set./dez., 2016. 